their rounds are not aware exactly on what their patients are resting. For the comfort of those patients it may be worth while to ask.-I am, etc.,

Watford, Herts.

J. W. C. LEECH

\section{Amoxycillin Rash in Infectious} Mononucleosis

SIR,-Ampicillin when given in infectious mononucleosis is known to produce a morbilliform rash changing after a few days to a typical copper colour and clearing spontaneously after 10-14 days.

I wish to report that in two cases of infectious mononucleosis (blood film and Paul-Bunnell positive) in teenage girls a similar eruption resulted from the administration of amoxycillin (Amoxil).-I am, etc.,

RONALD MULROY

Chapelthorpe,
near Wakefield

\section{Treatment of Dextropropoxyphene Poisoning}

SIR,-Overdosage with compounds containing dextropropoxyphene is unusual, and the possibility of effective treatment with nalorphine is not widely recogniz:d. The following case history records rapid recovery from a large overdose of Distalgesic, each tablet of which contains $32.5 \mathrm{mg}$ of dextropropoxyphene and $325 \mathrm{mg}$ of paracetamol.

A 27-year-old hotel chambermaid was admitted to the Casualty department of this hospital after taking a deliberate overdose of 25/30 Distalgesic tablets, together with half a bottle a sherry, within the previous hour. She was fully conscious on admission, with normal reflexes and no external stigmata of parenteral opiate addiction. During the preliminary interview she collapsed, becoming unresponsive with constricted pupils, and respiration ceased abruptly. Intubation and artificial ventilation were carried out, and after a non-productive stomach washout $10 \mathrm{mg}$ of nalorphine was given intravenously. Spontaneous breathing returned immediately and she started to open her eyes. In a few minutes respiratory efforts were sufficiently adequate to allow extubation, although a further $10 \mathrm{mg}$ of nalorphine was given over the next 10 minutes to counteract a fall in tidal volume. She then regained consciousness and, after a short period of restlessness, was transferred to the intensive care unit.

There have been a few reports of the treatment of dextropropoxyphene poisoning with nalorphine, with mixed results. ${ }^{1-3}$ In these cases the presenting features included generalized convulsions, which the above patient did not develop. The abruptness of her collapse and dramatic response to nalorphine emphasize the importance of identifying the causative agent in cases of poisoning, and where possible administering a suitable antidote.-I am, etc.,

Middlesex Hospital, 1 Karliner, J. S., Fournal of the American Medical
Association. i967, 199, 1006.

Swarts, C. $\mathrm{L} .96$ American Journal of Diseases of

3 Cawood, R.. and Thirkettle, J. L., British Medical fournal, 1966, 2, 1324.

\section{Chambers and the Periphery}

SIR,-I am constantly reading that the B.M.A.'s peripheral machinery will have to be reorganized to line up with the reorganized N.H.S. The only reason I have been given for the need to do this is Sir Paul Chambers's assumption that the Association was going to provide the advisory medical machinery for the area health authorities. Surely no one believes this was ever a possibility. Already the shadow medical advisory machinery for the area health authorities is being set up. What do we find? It is not being drawn from the B.M.A. at all but from the local medical committees and hospital staff committees.

One may well ask what role can the B.M.A. play in all this? In my view, this should remain advisory and supportive. Most of the active members of the L.M.C.s and hospital staff committees will be B.M.A. members and, constantly provided with information on current issues from headquarters, will ensure that B.M.A. policy will be observed. The B.M.A. division is a good forum for doctors to meet and discuss their problems. With increasing specialization it is impossible for a division to possess sufficient accurate knowledge of the problems of any one specialty to be able to advise an area health authority. I think Sir Paul forgot that all doctors are not in the N.H.S.; in this part of the country we have quite a considerable number of retired doctors, all members of the B.M.A., but with little desire to become embroiled in medical politics.

Having been a member for many years, I readily admit the debt the profession owes to the handful of members who take up the cudgels on our behalf. They are indispensable in protecting the interests and honour of the profession in the presence of a monopoly employer. I fail to see the need to reorganize.-I am, etc.

A. H. Holmes

St. Asaph, Flintshire North Wales Branch of B.M.A.

\section{Earnings of General Practitioners}

SIR,-We note with interest and some surprise a report which appeared in the Daily Telegraph of 14 February. This contained remarks attributed to a spokesman of the Regional Hospital Consultants and Specialists Association referring, in passing, to family doctors' pay: "Although G.P.s . . . have a net average income of just over $£ 5,500$. . . with special allowances for items like cars and telerhones the average basic income is nearer $£ 7,000$."

There is no telephone allowance payable to general practitioners, nor, with the exception of a mileage allowance paid to certain rural doctors, is there a car allowance. In this district we are informed reliably that there is no doctor receiving such an allowance. As part of the trading expense incurred in the pursuit of practice both telephone charges and a proportion of car expenses may be offset against income tax. It is, however, difficult to see how these tax allowances could increase a family doctor's income by $£ 1,500$.

The report goes on to state ... general practitioners were also able to increase their income substantially with extra work ... The actual income of G.P.s may, therefore, be as much as $\$ 10.000$."

There is no doubt that it is possible to supplement practice-derived income with insurance examinations, lectures, and even private patients, but we find it impossible to believe that in a district such as this it would be possible to earn $£ 3,000$ per annum outside the National Health Service. It is, of course, possible that even the Daily Telegraph may have misquoted the spokesman concerned.-We are, etc.,
D. J. ANDERSON
G. S. Cruickshank
N. KITCHING
J. A. L. MORRELL
R. D. MERSON
J. S. RIDDELL
A. F. RITCHIE
B. SCAIFE
J. L. MERSON
J. STOHLNER
M. TOWNEND

Queens Park Medical Centre,
Stockton-on-Tees, Teeside

\section{S.H.M.O.s and Medical Assistants}

SIR,-A review of senior hospital medical officers with allowances is currently going on with the object of personal upgrading to consultant status. It is therefore an ironic commentary on the state of mind of those responsible for the so-called new look in hospital staffing to read (Supplemen', 17 February, p. 45) that the Medical Assistants' Subcommittee of the Central Committee for Hospital Medical Services has recommended that certain medical assistants should receive a special allowance and that the recipients should be eligible for personal upgrading to consultant status.

The criticism of persons like myself would seem to be justified that this grade would perpetuate long-standing evils and solve nothing. O tempora, o mores! $-\mathrm{I}$ am, etc.,

I. M. LIBRACH

Chadwell Heath Hospital, Romford

\section{Points from Letters}

\section{Removing Obstructed Balloon Catheter}

Mr. A. J. WARrington (St. Luke's Hospital Malta) writes: The letter from Mr. S. C. Sood and Dr. H. Sahota (23 December, p. 735) prompts me to report a similar case which I encountered recently. A 76-year-old female patient was catheterized with a No. 18 latex rubber Foley catheter, the balloon being inflated with $10 \mathrm{ml}$ of sterile water. On attempting to remove the catheter two days later, it was found that the balloon could not be deflated with a syringe. The catheter was cut across but no fluid emerged from the inflating channel. Like your correspondents I considered overinflation of the balloon and injecting ether or paraffin too danoerous. A simple manoeuvre was finally resorted to. Gentle traction was applied to the catheter stump and the balloon was located from the vagina. A fine sterile hypodermic needle was passed through the anterior vaginal wall into the bladder in order to puncture the balloon. The catheter was then easily withdrawn.

\section{Smallpox Rash}

Dr. W. F. JACKSON (Southampton) writes: It is customary to describe the rash of smallpox as "centrifugal" in distribution, and this description is perpetuated in at least two recent accounts. I think this is a potentially misleading description. Certainly the rash will appear more dense peripherally at any stage of the illness, but its progression will usually be centripetal. The rash tends to spread towards the trunk, and not away from it. In temporal terms the smallpox rash is never "centrifugal." 